\title{
Non contiguous-finished genome sequence and description of Alistipes obesi sp. nov
}

\author{
Perrine Hugon ${ }^{1}$, Dhamodharan Ramasamy ${ }^{1}$, Jean-Christophe Lagier ${ }^{1}$, Romain $^{\text {Rivet }}{ }^{1}$, \\ Carine Couderc ${ }^{1}$, Didier Raoult ${ }^{1}$ and Pierre-Edouard Fournier ${ }^{1}$ वा \\ ${ }^{1}$ Aix-Marseille Université, Faculté de médecine, Marseille, France \\ *Corresponding author: Pierre-Edouard Fournier (pierre-edouard.fournier@univmed.fr)
}

Keywords: Alistipes obesi, genome, culturomics, taxono-genomics

\begin{abstract}
Alistipes obesi sp. nov. strain ph8 ${ }^{\top}$ is the type strain of $A$. obesi, a new species within the genus Alistipes. This strain, whose genome is described here, was isolated from the fecal flora of a 26-year-old woman suffering from morbid obesity. A. obesi is an obligately anaerobic rod. Here we describe the features of this organism, together with the complete genome sequence and annotation. The 3,162,233 bp long genome (1 chromosome but no plasmid) contains 2,623 protein-coding and 49 RNA genes, including three rRNA genes.
\end{abstract}

\section{Introduction}

Alistipes obesi strain ph8 ${ }^{\mathrm{T}}$ (CSUR= P186, DSMZ= 25724 ) is the type strain of $A$. obesi sp. nov. This bacterium is a Gram-negative, anaerobic, indolenegative bacillus and was isolated from the stool of a French patient suffering from morbid obesity as part of a culturomics study aiming at cultivating individually all species within human feces [1].

We recently proposed that genomic and proteomic data, which do not suffer from the lack of reproducibility and inter-laboratory comparability that the "gold standard" DNA-DNA hybridization and $\mathrm{G}+\mathrm{C}$ content determination does [2], may be included in the official description of new bacterial species [3-14].

The genus Alistipes (Rautio et al. 2003) [15] is currently comprised of five species, including $A$. finegoldii (Rautio et al. 2003) [15], A. indistinctus (Nagai et al. 2010) [16], A. onderdonkii (Song et al. 2006) [17], A. putredinis (Rautio et al. 2003) [15], and $A$. shahii (Song et al. 2006) [17]. In addition, we recently described two new species, $A$. senegalensis (Mishra et al. 2012) [6] and A. timonensis (Lagier et al. 2012) [7] that were isolated from the digestive microbiota from an asymptomatic Senegalese patient [1]. Members of the genus Alistipes are strictly anaerobic Gram-negative rods that are closely related to the Bacteroides fragilis group, with which they share the characteristic of bile-resistance and indole-positivity. Most Alistipes species have been isolated from human specimens, including the normal intestinal flora [17] and in cases of bacteremia, appendicitis, perirectal and brain abscess [18-20]. A 16S rRNA phylogenetic analysis revealed that $A$. obesi was closely related to $A$. shahii, A. senegalensis and $A$. timonensis. To the best of our knowledge, $A$. obesi sp. nov. is the first Alistipes species isolated from the digestive flora of an obese patient.

Here we present a summary classification and a set of features for $A$. obesi sp. nov. strain ph8 ${ }^{\mathrm{T}}$ together with the description of the complete genome sequencing and annotation. These characteristics support the circumscription of the species A. obesi.

\section{Classification and features}

A stool sample was collected from an obese, 26year-old woman living in Marseille, France, who suffered from morbid obesity: BMI=48.2 (118.8 $\mathrm{kg}, 1.57$ meter). At the time of stool sample collection she was not a drug user and was not on a diet. The patient gave an informed and signed consent, and the agreement of the local ethics committee of the IFR48 (Marseille, France) was obtained under agreement 11-017. The fecal specimen was preserved at $-80^{\circ} \mathrm{C}$ after collection. Strain ph8 (Table 1) was isolated in 2011 by anaerobic cultivation at $37^{\circ} \mathrm{C}$ on $5 \%$ sheep blood-enriched Columbia agar (BioMerieux, Marcy l'Etoile, France), after 11 days of preincubation of the stool sample with addition of rumen fluid in an anaerobic blood culture bottle. 
This strain exhibited a 93.5\% 16S rRNA sequence similarity with A. shahii (Song et al. 2006) [17], the phylogenetically closest validated Alistipes species (Figure 1), and 94.26 and $93.38 \%$ with $A$. senegalensis (Mishra et al. 2012) [6] and $A$. timonensis (Lagier et al. 2012) [7], respectively. Among validly published Alistipes species [31], the percentage of $16 \mathrm{~S}$ rRNA sequence similarity ranges from $90.5 \%$ between $A$. indistinctus (Nagai et al.
2010) [16] and A. shahii (Song et al. 2006) [17], to $96.8 \%$ between $A$. finegoldii (Rautio et al. 2003) [8] and A. onderdonkii (Song et al. 2006) [17]. As a consequence, and despite the fact that strain ph8 exhibited a 16SrRNA sequence similarity with the nearest validly published species lower than the 95.0\% cutoff usually regarded as a threshold for the creation of new genus [32], we considered it as a new species within the genus Alistipes.

Table 1. Classification and general features of Alistipes obesi strain ph $8^{\top}$ according to the MIGS recommendations [21]

\begin{tabular}{|c|c|c|c|}
\hline MIGS ID & Property & Term & Evidence code \\
\hline & \multirow{8}{*}{ Current classification } & Domain Bacteria & TAS [22] \\
\hline & & Phylum Bacteroidetes & TAS $[23,24]$ \\
\hline & & Class Bacteroidia & TAS $[23,25]$ \\
\hline & & Order Bacteroidales & TAS $[23,26]$ \\
\hline & & Family Rikenellaceae & TAS $[23,27]$ \\
\hline & & Genus Alistipes & TAS $[28,29]$ \\
\hline & & Species Alistipes obesi & IDA \\
\hline & & Type strain ph $8^{\top}$ & IDA \\
\hline & Gram stain & Negative & IDA \\
\hline & Cell shape & Rod & IDA \\
\hline & Motility & Motile & IDA \\
\hline & Sporulation & Non sporulating & IDA \\
\hline & Temperature range & Mesophile & IDA \\
\hline & Optimum temperature & $37^{\circ} \mathrm{C}$ & IDA \\
\hline MIGS-6.3 & Salinity & Unknown & IDA \\
\hline \multirow[t]{3}{*}{ MIGS-22 } & Oxygen requirement & Anaerobic & IDA \\
\hline & Carbon source & Unknown & NAS \\
\hline & Energy source & Unknown & NAS \\
\hline MIGS-6 & Habitat & Human gut & IDA \\
\hline \multirow[t]{3}{*}{ MIGS-15 } & Biotic relationship & Free living & IDA \\
\hline & Pathogenicity & Unknown & NAS \\
\hline & Biosafety level & 2 & \\
\hline MIGS-14 & Isolation & Human feces & \\
\hline MIGS-4 & Geographic location & France & IDA \\
\hline MIGS-5 & Sample collection time & January 2011 & IDA \\
\hline MIGS-4.1 & Latitude & 43.296482 & IDA \\
\hline MIGS-4.1 & Longitude & 5.36978 & IDA \\
\hline MIGS-4.3 & Depth & Surface & IDA \\
\hline MIGS-4.4 & Altitude & $0 \mathrm{~m}$ above sea level & IDA \\
\hline
\end{tabular}

Evidence codes - IDA: Inferred from Direct Assay; TAS: Traceable Author Statement (i.e., a direct report exists in the literature); NAS: Non-traceable Author Statement (i.e., not directly observed for the living, isolated sample, but based on a generally accepted property for the species, or anecdotal evidence). These evidence codes are from the Gene Ontology project [30]. If the code is IDA, then the property was directly observed for a live isolate by one of the authors or an expert mentioned in the acknowledgements. 


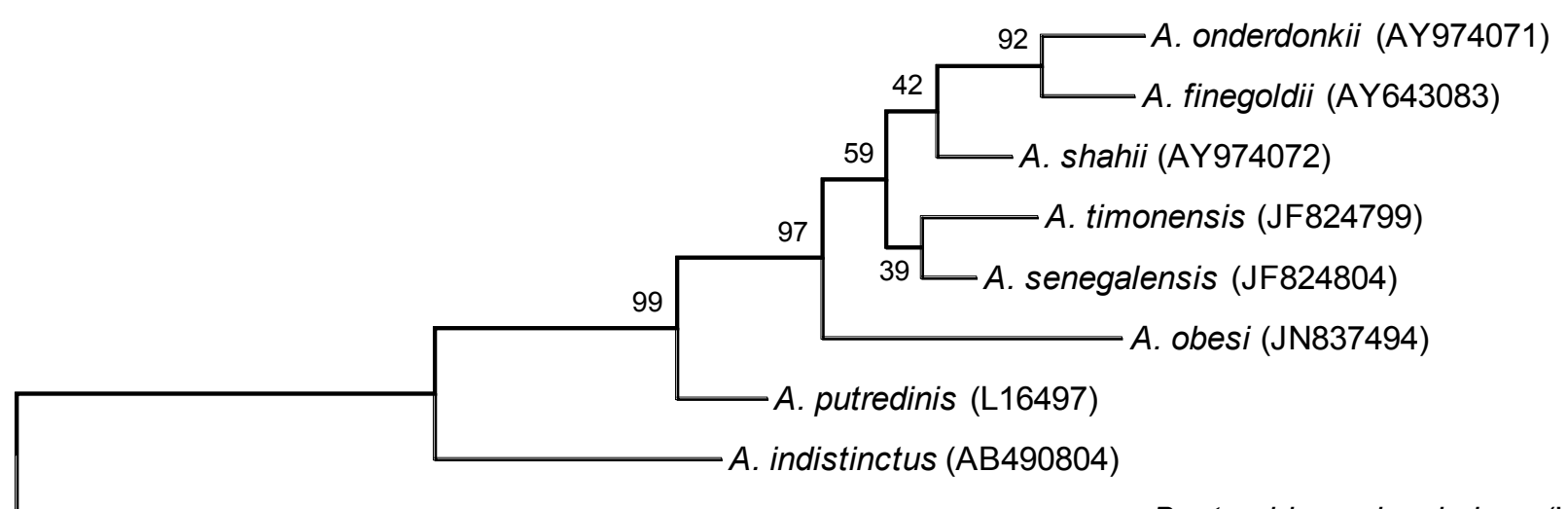

Bacteroides splanchnicus (L16496)

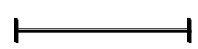

Figure 1. Phylogenetic tree highlighting the position of Alistipes obesi strain ph $8^{\top}$ relative to other type strains within the genus Alistipes. Genbank accession numbers are indicated in parentheses. Sequences were aligned using ClustalW, and phylogenetic inferences obtained using the maximum-likelihood method within the MEGA software. Numbers at the nodes are bootstrap values obtained by repeating the analysis 500 times to generate a majority consensus tree. Bacteroides splanchnicus was used as an outgroup. The scale bar represents a $2 \%$ nucleotide sequence divergence.

Different growth temperatures $\left(25,30,37,45^{\circ} \mathrm{C}\right)$ were tested; no growth occurred at $25^{\circ} \mathrm{C}$ or $30^{\circ} \mathrm{C}$, growth occurred between $37^{\circ} \mathrm{C}$ and $45^{\circ} \mathrm{C}$, and optimal growth was observed at $37^{\circ} \mathrm{C}$. Colonies were $0.5 \mathrm{~mm}$ in diameter on $5 \%$ blood-enriched Columbia agar, are translucent and light grey. Growth of the strain was tested under anaerobic and microaerophilic conditions using GENbag anaer and GENbag microaer systems, respectively (BioMerieux), and in the presence of air, with or without $5 \% \mathrm{CO}_{2}$. Optimal growth was achieved anaerobically. No growth was observed under aerobic and microaerophilic conditions. Gram staining showed Gram-negative rods (Figure 2). A motility test was positive. Cells grown on agar and diameter ranged from $0.44 \mu \mathrm{m}$ to $0.76 \mu \mathrm{m}$, with a mean diameter of $0.61 \mu \mathrm{m}$ by electron microscopy (Figure 3). Comparison between seven Alistipes strains is presented in Table 2 .

Strain ph8 ${ }^{\mathrm{T}}$ exhibited catalase activity but was not oxidase positive. Using the API RAPID ID 32A (BioMerieux), a positive reaction was obtained for $\alpha$-galactosidase, $\quad \beta$-galactosidase, $\quad \mathrm{N}$-acetyl- $\beta$ glucosaminidase, alkaline phosphatase, leucyl glycine arylamidase, and alanine arylamidase. All other tested reactions were negative, notably nitrate reduction, indole formation, urease, arginine dihydrolase, $\alpha$ - and $\beta$-glucosidase, 6-phospho- $\beta$ galactosidase, arginine arylamidase, proline arylamidase, phenylalanine arylamidase, leucine arylamidase, pyroglutamic acid arylamidase, tyrosine arylamidase, glycine arylamidase, histidine arylamidase, glutamyl glutamic acid arylamidase, serine arylamidase, and mannose and raffinose fermentation. Using the Api Zym system (BioMerieux), esterase, esterase lipase, acid phosphatase, Naphtol-AS-BI phosphohydrolase and $\alpha-$ galactosidase activities were positive. A. obesi is susceptible to imipenem, ciprofloxacin, metronidazole, nitrofurantoin and rifampicin, but resistant to penicillin G, amoxicillin, amoxicillin-clavulanic acid, erythromycin, vancomycin, gentamicin 15 and gentamycin 500, doxycycline, ceftriaxone and trimethoprim/sulfamethoxazole. By comparison with $A$. senegalensis, $A$. obesi differed in motility, $\alpha$ galactosidase, $\beta$-galactosidase, indole production, $\beta$-glucuronidase, arginine arylamidase, glycine arylamidase, proline arylamidase and mannose fermentation [6]. By comparison with $A$. timonensis, A. obesi differed in motility, indole production, $\beta$ glucuronidase and $\mathrm{N}$-acetyl- $\beta$-glucosaminidase [7]. By comparison with A.putredinis, A.obesi differed in motility, $\alpha$-galactosidase, $\beta$-galactosidase $\mathrm{N}$-acetyl$\beta$-glucosaminidase and indole production [15]. By comparison with A.finegoldii, A.obesi differed in catalase, $\alpha$-glucosidase and indole production [15]. Finally, A. obesidiffered in indole production, catalase, esterase, esterase lipase and alpha-glucosidase with $A$. shahii [17], and alpha-glucosidase, esterase, esterase lipase and acid phosphatase with $A$. indistinctus [16]. 
Table 2. Differential characteristics of Alistipes strains. $\dagger$

\begin{tabular}{|c|c|c|c|c|c|c|c|}
\hline Properties & A.obesi & A.timonensis & A.senegalensis & A.putredinis & A.finegoldii & A.shahii & A.indistinctus \\
\hline Cell diameter $(\mu \mathrm{m})$ & 0.61 & 0.62 & 0.56 & 0.40 & 0.20 & 0.15 & 0.60 \\
\hline Oxygen requirement & anaerobic & anaerobic & $\begin{array}{l}\text { anaerobic } \\
\text { facultative }\end{array}$ & anaerobic & anaerobic & anaerobic & anaerobic \\
\hline Gram stain & - & - & - & - & - & - & - \\
\hline Salt requirement & na & na & na & na & na & na & na \\
\hline Motility & + & - & - & - & na & na & na \\
\hline Endospore formation & na & na & na & - & - & na & - \\
\hline \multicolumn{8}{|l|}{ Production of } \\
\hline Alkaline phosphatase & + & na & na & na & + & + & + \\
\hline Acid phosphatase & + & na & na & na & + & + & w \\
\hline Catalase & + & + & + & var & - & - & + \\
\hline Oxidase & - & - & - & na & na & na & - \\
\hline Nitrate reductase & - & na & na & - & - & - & - \\
\hline Urease & - & na & na & na & na & na & - \\
\hline ogalactosidase & + & + & w & - & + & + & + \\
\hline ß3alactosidase & + & + & w & - & + & + & + \\
\hline Bglucuronidase & - & + & w & na & na & - & $+/-$ \\
\hline aglucosidase & - & na & na & na & + & + & + \\
\hline Esterase & + & na & na & na & + & w & w \\
\hline Esterase lipase & + & na & na & na & + & w & w \\
\hline Indole & - & w & w & + & + & + & - \\
\hline $\begin{array}{l}\mathrm{N} \text {-acetyl- } \beta \\
\text { glucosaminidase }\end{array}$ & + & w & na & - & + & + & + \\
\hline Arginine arylamidase & - & na & w & na & na & na & - \\
\hline $\begin{array}{l}\text { glutamic acid decar- } \\
\text { boxylase }\end{array}$ & na & + & na & + & na & na & - \\
\hline $\begin{array}{l}\text { Leucyl glycine } \\
\text { arylamidase }\end{array}$ & + & + & + & na & na & + & + \\
\hline Alanine arylamidase & + & + & + & na & na & + & + \\
\hline Proline arylamidase & - & na & + & na & na & na & - \\
\hline Glycine arylamidase & - & na & w & na & na & na & - \\
\hline \multicolumn{8}{|l|}{ Utilization of } \\
\hline $\begin{array}{l}\text { D-mannose } \\
\text { Habitat }\end{array}$ & $\begin{array}{l}\text { human } \\
\text { gut }\end{array}$ & $\begin{array}{l}\text { human } \\
\text { gut }\end{array}$ & $\underset{\text { gut }}{\stackrel{+}{\text { human }}}$ & $\begin{array}{c}\text { na } \\
\text { human }\end{array}$ & $\begin{array}{l}\text { na } \\
\text { Human } \\
\text { gut }\end{array}$ & $\begin{array}{l}\stackrel{+}{\text { human }} \\
\text { gut }\end{array}$ & $\begin{array}{l}\text { human } \\
\text { gut }\end{array}$ \\
\hline $\begin{array}{l}\text { var: variable } \\
\text { w: weak } \\
\text { na: data not availa- } \\
\text { ble } \\
\text { +/-: depending on } \\
\text { tests used }\end{array}$ & & & & & & & \\
\hline
\end{tabular}

${ }^{\dagger}$ A. obesi sp. nov strain ph8 ${ }^{\top}$, Alistipes timonensis strain $\mathrm{JC} 136^{\top}$, Alistipes senegalensis strain JC50 ${ }^{\top}$, Alistipes putredinis strain ATCC $29800^{\top}$, Alistipes finegoldii strain AHN $2437^{\top}$, Alistipes shahii strain ATCC BAA-1179 ${ }^{\top}$ and Alistipes indistinctus strain YIT 12060 ${ }^{\top}$. 
Matrix-assisted laser-desorption/ionization timeof-flight (MALDI-TOF) MS protein analysis was carried out as previously described [33]. Briefly, a pipette tip was used to pick one isolated bacterial colony from a culture agar plate, and to spread it as a thin film on a MTP 384 MALDI-TOF target plate (Bruker Daltonics, Leipzig, Germany). Four distinct deposits were done for strain ph8 from four isolated colonies. Each smear was overlaid with $2 \mu \mathrm{L}$ of matrix solution (saturated solution of alpha-cyano-4-hydroxycinnamic acid) in 50\% acetonitrile, $2.5 \%$ tri-fluoracetic-acid, and allowed to dry for five minutes. Measurements were performed with a Microflex spectrometer (Bruker). Spectra were recorded in the positive linear mode for the mass range of 2,000 to 20,000 Da (parameter settings: ion source 1 (IS1), $20 \mathrm{kV}$; IS2, $18.5 \mathrm{kV}$; lens, $7 \mathrm{kV}$ ). A spectrum was obtained after 675 shots at a variable laser power. The time of acquisition was between 30 seconds and 1 minute per spot. The four ph8 spectra were imported into the MALDI BioTyper software (version 2.0, Bruker) and analyzed by standard pattern matching (with default parameter settings) against the main spectra of 3,769 bacteria including the spectra from $A$. finegoldii, A. onderdonkii, A. shahii, A. senegalensis and $A$. timonensis used as reference data, in the BioTyper database. The method of identification included the $\mathrm{m} / \mathrm{z}$ from 3,000 to $15,000 \mathrm{Da}$. For every spectrum, 100 peaks at most were taken into account and compared with spectra in the database. A score enabled either an identification, or non-identification, from the tested species: a score $>2$ with a validly published species enabled a presumed identification at the species level, a score $>1.7$ but $<2$ enabled a presumed identification at the genus level; and a score $<1.7$ did not enable an identification. For strain ph8, the obtained score was 1.1, suggesting that this isolate was not a member of a known species. We incremented our database with the spectrum from strain ph8 (Figure 4). Finally, the gel view allows us to highlight the spectra differences with other of Alistipes genera members (Figure 5).

\section{Genome sequencing information}

The organism was selected for sequencing on the basis of its phylogenetic position and 16S rRNA similarity to other members of the genus Alistipes, and is part of a study of the human digestive flora aiming at isolating all bacterial species contained within human feces. It was the seventh genome of an Alistipes species and the first genome of Alistipes obesi sp. nov. The EMBL accession number is CAHA00000000 and consists of 59 contigs. Table 3 shows the project information and its association with MIGS version 2.0 compliance [21].

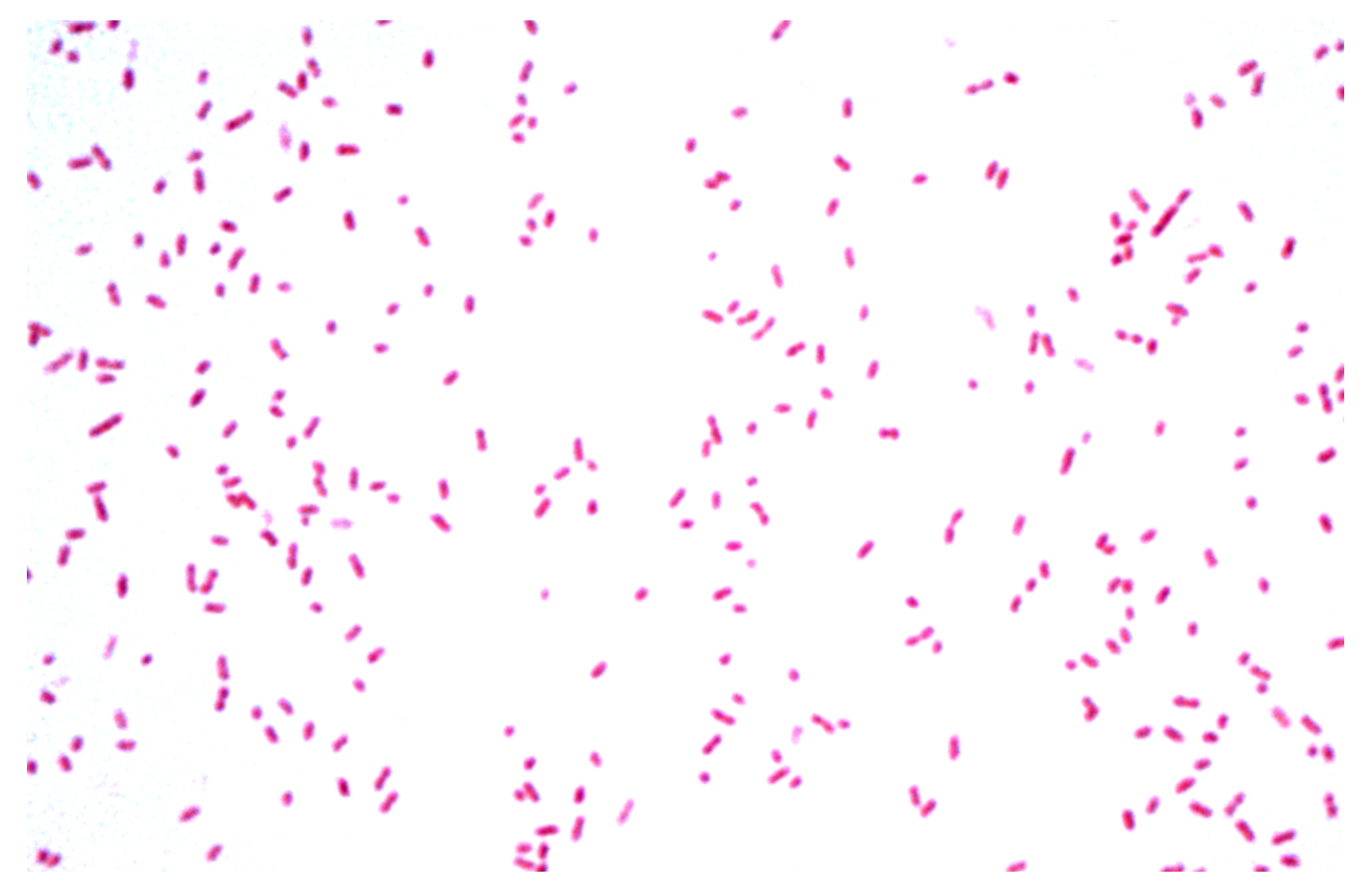

Figure 2. Gram staining of $A$. obesi strain ph $8^{\top}$ 


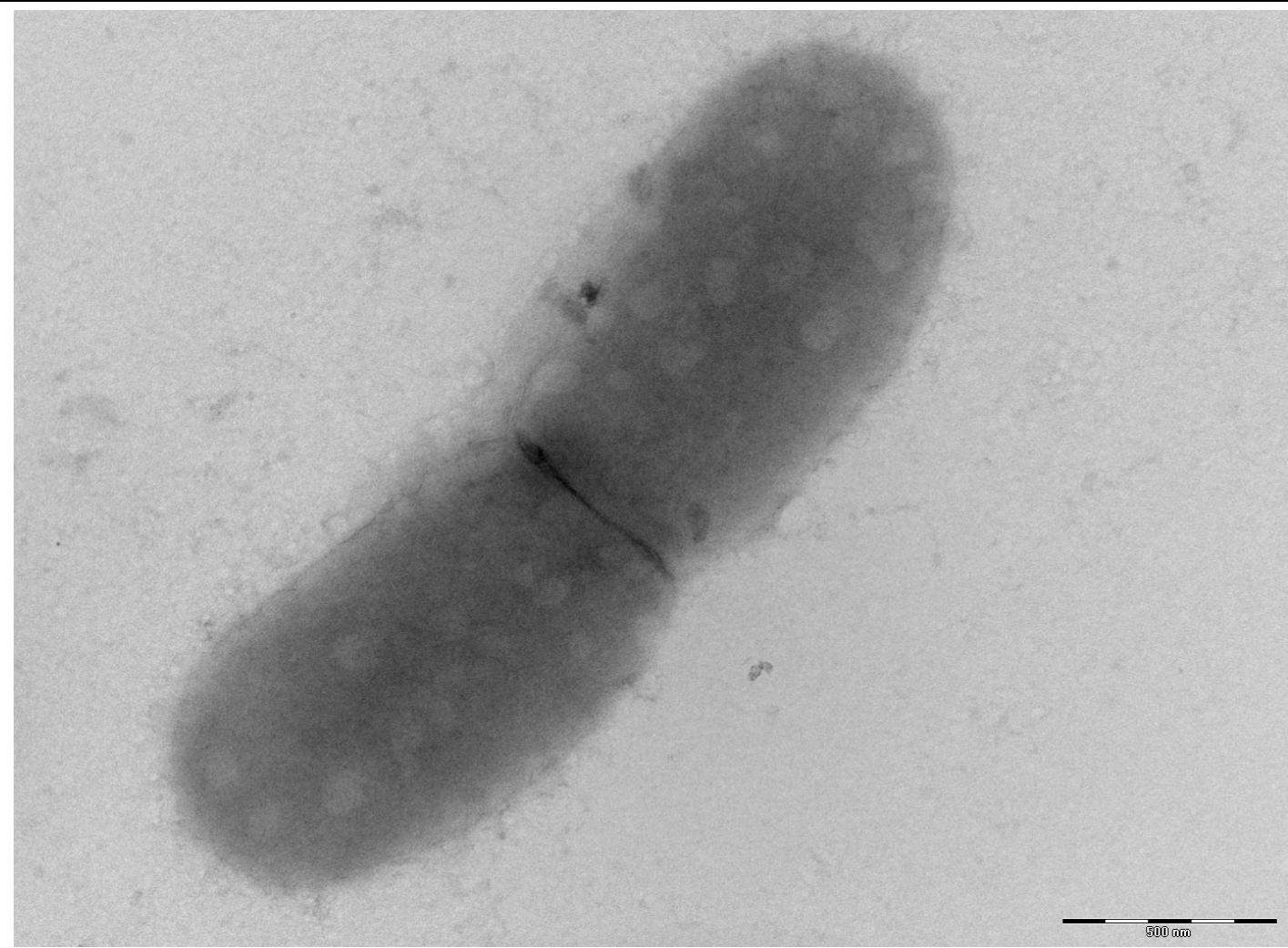

Figure 3. Transmission electron microscopy of $A$. obesi strain ph $8^{\top}$, using a Morgani 268D (Philips) at an operating voltage of $60 \mathrm{kV}$. The scale bar represents $500 \mathrm{~nm}$.

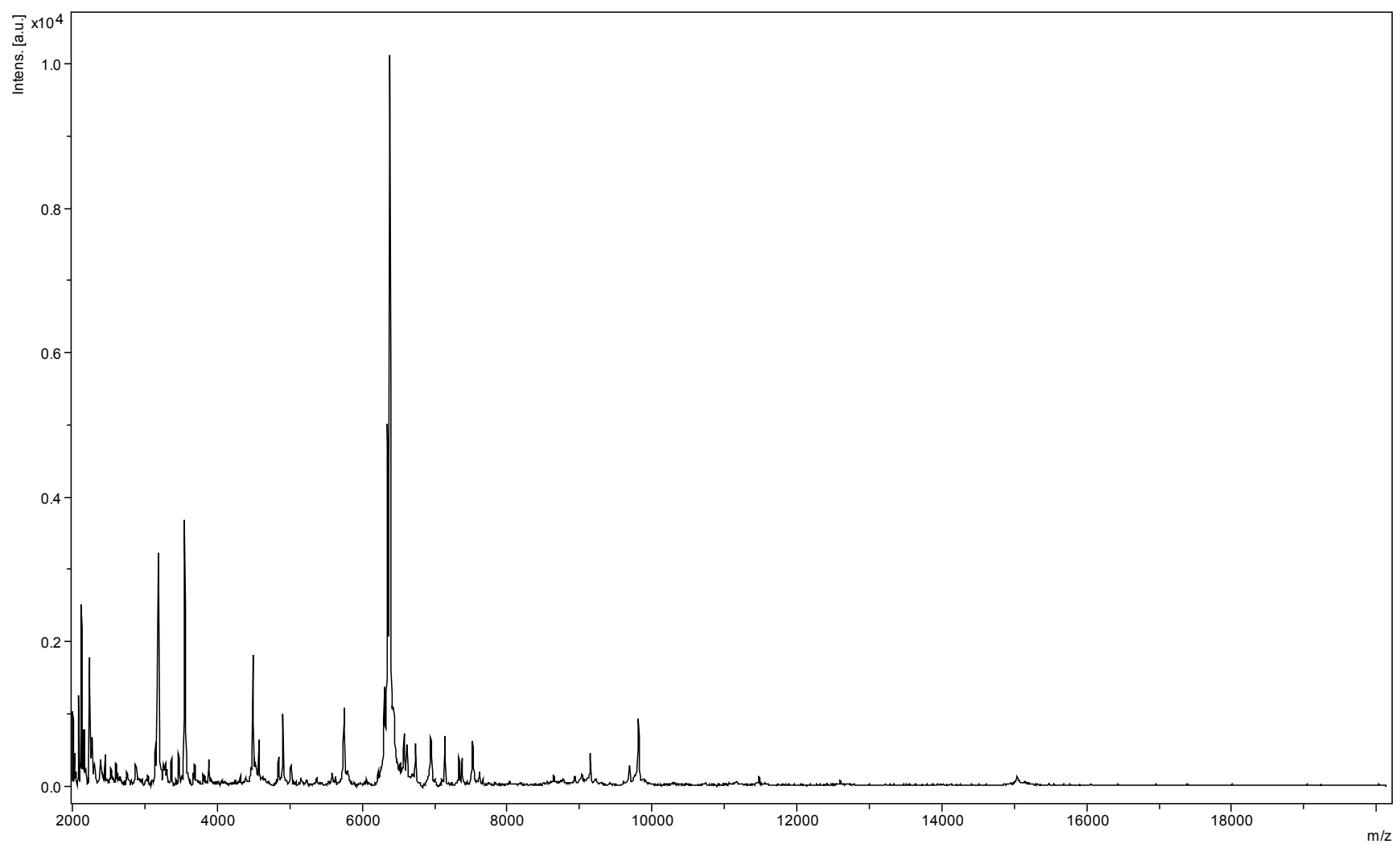

Figure 4. Reference mass spectrum from $A$. obesi strain $p h 8^{\top}$. Spectra from 4 individual colonies were compared and a reference spectrum was generated. 


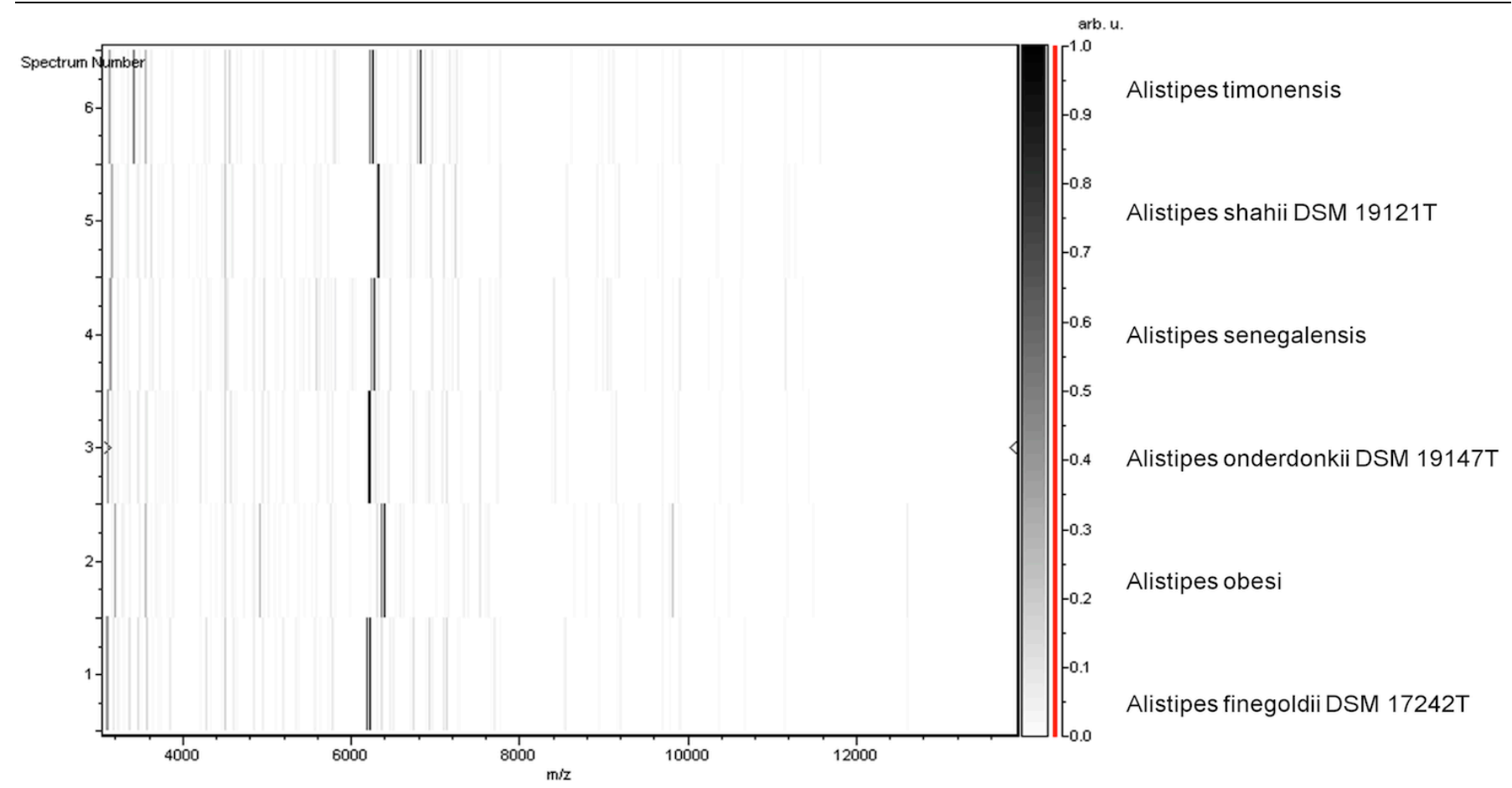

Figure 5. Gel view comparing Alistipes obesi ph $^{\top}$ spectra with other members into Alistipes genera (Alistipes timonensis, Alistipes senegalensis, Alistipes shahii, Alistipes onderdonkii and Alistipes finegoldii). The Gel View displays the raw spectra of all loaded spectrum files arranged in a pseudo-gel like look. The $x$-axis records the $\mathrm{m} / \mathrm{z}$ value. The left $y$-axis displays the running spectrum number originating from subsequent spectra loading. The peak intensity is expressed by a Gray scale scheme code. The color bar and the right y-axis indicate the relation between the color a peak is displayed with and the peak intensity in arbitrary units.

Table 3. Project information

\begin{tabular}{|c|c|c|}
\hline MIGS ID & Property & Term \\
\hline MIGS-31 & Finishing quality & High-quality draft \\
\hline MIGS-28 & Libraries used & One paired end 3-kb library and one Shotgun library \\
\hline MIGS-29 & Sequencing platforms & 454 GS FLX Titanium \\
\hline MIGS-31.2 & Fold coverage & $18 \times$ \\
\hline MIGS-30 & Assemblers & Newbler version 2.5 .3 \\
\hline \multirow[t]{4}{*}{ MIGS-32 } & Gene calling method & Prodigal \\
\hline & EMBL ID & CAHA00000000 \\
\hline & EMBL Date of Release & May 30, 2012 \\
\hline & Project relevance & Study of the human gut microbiome \\
\hline
\end{tabular}




\section{Growth conditions and DNA isolation}

A. obesi sp. nov. strain ph8 ${ }^{\mathrm{T}}$ (CSUR $=\mathrm{P} 186$, $\mathrm{DSM}=25724$ ), was grown anaerobically on $5 \%$ sheep blood-enriched Columbia agar (BioMerieux) at $37^{\circ} \mathrm{C}$. Four petri dishes were spread and resuspended in $3 \times 100 \mu$ l of G2 buffer (EZ1 DNA Tissue kit, Qiagen, Hilden, Germany). A first mechanical lysis was performed by glass powder on the Fastprep-24 device (MP Biomedicals, Santa Ana, CA, USA) using $2 \times 20$ seconds cycles. DNA was then treated with $2.5 \mu \mathrm{g} / \mu \mathrm{L}$ lysozyme for 30 minutes at $37^{\circ} \mathrm{C}$ and extracted using the BioRobot EZ 1 Advanced XL (Qiagen). The DNA concentration was measured at $120.7 \mathrm{ng} / \mu \mathrm{L}$ using the Genios fluorometer (Tecan, Lyon, France).

\section{Genome sequencing and assembly}

Five $\mu \mathrm{g}$ of DNA was mechanically fragmented on a Hydroshear device (Digilab, Holliston, MA,USA) with an enrichment size at $3-4 \mathrm{~kb}$. The DNA fragmentation was visualized using the 2100 BioAnalyzer (Agilent, Massy, France) on a DNA labchip 7500 with an optimal size of $3.213 \mathrm{~kb}$. A 3$\mathrm{kb}$ paired-end library was constructed using the GS Rapid library Prep kit (Roche) according to the 454 GS FLX Titanium paired-end protocol. Circularization and nebulization were performed and generated a pattern with an optimal size of $454 \mathrm{bp}$. After PCR amplification through 15 cycles followed by double size selection, the single stranded paired-end library was then quantified using the Genios fluorometer (Tecan) at 390 $\mathrm{pg} / \mu \mathrm{L}$. The library concentration equivalence was calculated as $1.58 \mathrm{E}+08$ molecules $/ \mu \mathrm{L}$. The library was stored at $-20^{\circ} \mathrm{C}$ until further use.

The paired-end library was clonally-amplified with $1 \mathrm{cpb}$ in 4 SV-emPCR reactions with the GS Titanium SV emPCR Kit (Lib-L) v2 (Roche). The yield of the emPCR was $18.6 \%$, in the 5 to $20 \%$ range recommended by the Roche procedure. Approximately 790,000 beads were loaded on one quarter region of a GS Titanium PicoTiterPlate PTP Kit $70 \times 75$ and sequenced with the GS FLX Titanium Sequencing Kit XLR70 (Roche). The run was performed overnight and then analyzed on the cluster through the gsRunBrowser and Newbler assembler (Roche). A total of 192,803 passed filter wells were obtained and generated $56.6 \mathrm{Mb}$ with a length average of $293.5 \mathrm{bp}$. The passed filter sequences were assembled using Newbler with $90 \%$ identity and 40 bp as overlap. The final assembly identified 3 scaffolds and 59 contigs ( $>1,500 \mathrm{bp})$, for a genome size of $3.16 \mathrm{Mb}$.

\section{Genome annotation}

Open Reading Frames (ORFs) were predicted using Prodigal [34] with default parameters but the predicted ORFs were excluded if they spanned a sequencing gap. The predicted bacterial protein sequences were searched against the GenBank database and the Clusters of Orthologous Groups (COG) databases using BLASTP. The tRNAScanSE tool [35] was used to find tRNA genes, whereas ribosomal RNAs were found by using RNAmmer [36] and BLASTn against GenBank. Signal peptides and transmembrane helices were predicted using SignalP [37] and TMHMM [38], respectively. ORFans were identified if their BLASTP $E$-value was lower than 1e-03 for alignment length greater than 80 amino acids. If alignment lengths were smaller than 80 amino acids, we used an $E$-value of $1 \mathrm{e}-05$. Such parameter thresholds have already been used in previous works to define ORFans. To estimate the mean level of nucleotide sequence similarity at the genome level between Alistipes obesi strain ph8T and other members of the Alistipes genera, we compared genomes two by two and determined the mean percentage of nucleotide sequence identity among orthologous ORFs using BLASTn. Orthologous genes were detected using the Proteinortho software [39]. We compared $A$. obesi strain ph8 ${ }^{\mathrm{T}}$ with $A$. finegoldii strain AHN 2437 (GenBank accession number CP003274), A. indistinctus strain YIT 12060 (ADLD00000000), A. putredinis strain DSM 17216 (ABFK00000000), A. senegalensis strain JC50 ${ }^{\mathrm{T}}$ (CAHI00000000), A. shahii strain WAL 8301 (FP929032) and A. timonensis strain JC136 ${ }^{\mathrm{T}}$ (CAEG00000000).

\section{Genome properties}

The genome is 3,162,233 bp long ( 1 chromosome, but no plasmid) with a $58.6 \% \mathrm{G}+\mathrm{C}$ content (Table 4, Figure 6). Of the 2,672 predicted genes, 2,623 were protein-coding genes and 49 were RNAs. A total of 1,409 genes (52.75\%) were assigned a putative function. One hundred twenty-seven genes were identified as ORFans (4.8\%). The remaining genes were annotated as hypothetical proteins. The distribution of genes into COGs functional categories is presented in Table 5. The properties and the statistics of the genome are summarized in Tables 4 and 5. 
Table 4. Nucleotide content and gene count levels of the genome

\begin{tabular}{lrr}
\hline Attribute & Value & \% of total $^{\mathbf{a}}$ \\
\hline Genome size (bp) & $3,162,233$ & \\
DNA coding region (bp) & $2,799,840$ & 88.53 \\
G+C content (bp) & $1,853,068$ & 58.6 \\
Total genes & 2,672 & 100 \\
RNA genes & 49 & 1.83 \\
Protein-coding genes & 2,623 & 98.16 \\
Genes with function prediction & 1,409 & 52.75 \\
Genes assigned to COGs & 1,559 & 58.36 \\
Genes with peptide signals & 429 & 16.06 \\
Genes with transmembrane helices & 512 & 19.16 \\
\hline
\end{tabular}

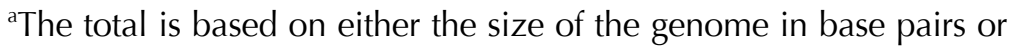
the total number of protein coding genes in the annotated genome.

Table 5. Number of genes associated with the 25 general COG functional categories

\begin{tabular}{|c|c|c|c|}
\hline Code & Value & $\%$ age $^{a}$ & Description \\
\hline J & 134 & 5.02 & Translation \\
\hline A & 1 & 0.04 & RNA processing and modification \\
\hline K & 67 & 2.51 & Transcription \\
\hline $\mathrm{L}$ & 114 & 4.27 & Replication, recombination and repair \\
\hline B & 0 & 0 & Chromatin structure and dynamics \\
\hline D & 19 & 0.71 & Cell cycle control, mitosis and meiosis \\
\hline $\mathrm{Y}$ & 0 & 0 & Nuclear structure \\
\hline V & 42 & 1.57 & Defense mechanisms \\
\hline $\mathrm{T}$ & 25 & 0.94 & Signal transduction mechanisms \\
\hline M & 129 & 4.83 & Cell wall/membrane biogenesis \\
\hline $\mathrm{N}$ & 5 & 0.19 & Cell motility \\
\hline Z & 0 & 0 & Cytoskeleton \\
\hline W & 0 & 0 & Extracellular structures \\
\hline$U$ & 19 & 0.71 & Intracellular trafficking and secretion \\
\hline $\mathrm{O}$ & 41 & 1.54 & Posttranslational modification, protein turnover, chaperones \\
\hline $\mathrm{C}$ & 103 & 3.86 & Energy production and conversion \\
\hline G & 108 & 4.04 & Carbohydrate transport and metabolism \\
\hline $\mathrm{E}$ & 90 & 3.37 & Amino acid transport and metabolism \\
\hline $\mathrm{F}$ & 45 & 1.68 & Nucleotide transport and metabolism \\
\hline $\mathrm{H}$ & 55 & 2.06 & Coenzyme transport and metabolism \\
\hline I & 38 & 1.42 & Lipid transport and metabolism \\
\hline $\mathrm{P}$ & 80 & 3.0 & Inorganic ion transport and metabolism \\
\hline Q & 6 & 0.22 & Secondary metabolites biosynthesis, transport and catabolism \\
\hline $\mathrm{R}$ & 202 & 7.56 & General function prediction only \\
\hline S & 86 & 3.22 & Function unknown \\
\hline- & 150 & 5.62 & Not in COGs \\
\hline
\end{tabular}

${ }^{a}$ The total is based on the total number of protein coding genes in the annotated genome 


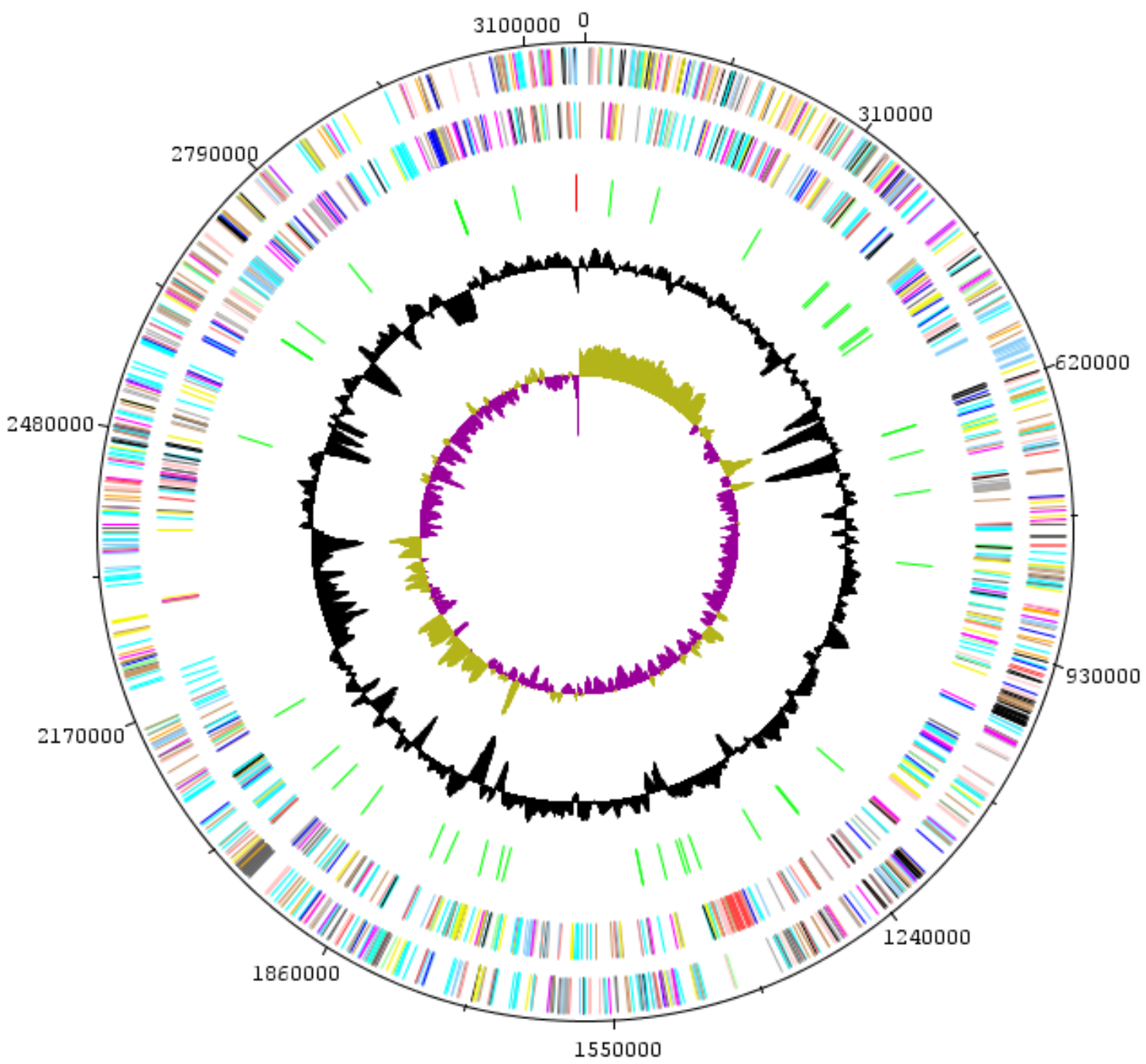

Figure 6. Graphical circular map of the chromosome. From outside to the center: Genes on forward strand (colored by COG categories), genes on reverse strand (colored by COG categories), RNA genes (tRNAs green, rRNAs red), GC content, GC skew.

\section{Comparison with the genomes of other}

\section{Alistipes species}

Currently, the genomes from six validly published Alistipes species: A. finegoldii strain DSM 17242 (GenBank accession number CP003274), A. indistinctus strain YIT 12060 (ADLD00000000), A. putredinis strain DSM 17216 (ABFK00000000) and A. shahii strain WAL 8301 (FP929032), A. senegalensis strain JC50 ${ }^{\mathrm{T}}$ (CAHI00000000) and $A$. timonensis strain JC136 ${ }^{\mathrm{T}}$ (CAEG00000000) are available. The draft genome of $A$. obesi is larger than $A$. indistinctus and $A$. putredinis (3.16 vs 2.85 and $2.55 \mathrm{Mb}$, respectively), but of a smaller size than $A$. finegoldii, A. shahii, A. senegalensis and A. timonensis $(3.73,3.76,4.01$ and $3.49 \mathrm{Mb}$, respectively). With the exception of $A$. timonensis, which exhibits a value of $58.8 \%$, A. obesi has a higher $\mathrm{G}+\mathrm{C}$ content than $A$. finegoldii, A. indistinctus, A. putredinis A. shahii and $A$. senegalensis (58.6 vs 56.6, 54.8, 53.3, 57.6 and $58.4 \%$, respectively. A. obesi has more predicted genes than $A$. indistinctus and $A$. putredinis $(2,619$ vs 2,342 and 2,335 respectively), but fewer than $A$. finegoldii, A. shahii, A. senegalensis or A. timonensis $(3,231,3,132,3,161$, and 2,709, respectively). In addition, A. obesi shared 1,417,1,462, 1,429, 1,431, 1,135 and 1,218 orthologous genes with $A$. timonensis, A. senegalensis, A. shahii, A. finegoldii, A. indistinctus and $A$. putredinis respectively. The average nucleotide sequence identity ranged from 69.70 to $90.98 \%$ among Alistipes species, and from 70.00 to $76.81 \%$ between A. obesi and other species, thus confirming its new species status (Table 6). 
Hugon et al.

Table 6. Number of orthologous genes (upper right), average nucleotide identity levels (lower left) between pairs of genomes and numbers of proteins per genome (bold) [39].

\begin{tabular}{lrrrrrrr}
\hline & A. obesi & A. timonensis & A. senegalensis & A. shahii & A. finegoldii & A. indistinctus & A. putredinis \\
\hline A. obesi & $\mathbf{2 , 6 1 9}$ & 1,417 & 1,462 & 1,429 & 1,431 & 1,135 & 1,218 \\
A. timonensis & 76.19 & $\mathbf{2 , 7 0 9}$ & 1,764 & 1,650 & 1,585 & 1,210 & 1,238 \\
A. senegalensis & 76.40 & 90.98 & $\mathbf{3 , 1 6 1}$ & 1,739 & 1,660 & 1,218 & 1,277 \\
A. shahii & 76.81 & 80.03 & 86.33 & $\mathbf{3 , 1 3 2}$ & 1,674 & 1,155 & 1,270 \\
A. finegoldii & 76.23 & 81.14 & 82.04 & 82.90 & $\mathbf{3 , 2 3 1}$ & 1,202 & 1,303 \\
A. indistinctus & 70.00 & 70.05 & 70.02 & 70.00 & 69.91 & $\mathbf{2 , 3 4 2}$ & 1,038 \\
A. putredinis & 74.49 & 75.21 & 75.32 & 75.50 & 76.23 & 69.70 & $\mathbf{2 , 3 3 5}$ \\
\hline
\end{tabular}

\section{Conclusion}

On the basis of phenotypic, phylogenetic and genomic analyses (taxono-genomics), we formally propose the creation of $A$. obesi sp. nov., which contains strain ph8 ${ }^{\mathrm{T}}$. This bacterium has been cultivated from an obese patient in Marseille, France.

\section{Description of Alistipes obesi sp. nov.}

Alistipes obesi (o.be.si. L. masc. gen. adj. obesi of an obese, the disease presented by the patient from whom the type strain ph8 ${ }^{\mathrm{T}}$ was isolated). Colonies are $0.5 \mathrm{~mm}$ in diameter and are translucent and light grey on blood-enriched Columbia agar. Cells are rod-shaped with a mean diameter of $0.61 \mu \mathrm{m}$. Optimal growth is achieved anaerobically. No growth is observed in aerobic or microaerophilic conditions. Growth occurs between $37^{\circ} \mathrm{C}-45^{\circ} \mathrm{C}$, with optimal growth observed at $37^{\circ} \mathrm{C}$.

Cells stain Gram negative and are motile. Catalase, $\alpha$-galactosidase, $\quad \beta$-galactosidase, $\quad \mathrm{N}$-acetyl- $\beta$ glucosaminidase, acid phosphatase, alkaline phosphatase, leucyl glycine arylamidase, alanine arylamidase, esterase, esterase lipase and

\section{Acknowledgements}

The authors thank the XEGEN company (www.xegen.fr) for automating the genomic annotation process. This

\section{References}

1. Lagier JC, Armougom F, Million M, Hugon P, Pagnier I, Robert C, Bittar F, Fournous G, Gimenez G, Maraninchi M, et al. Microbial culturomics: paradigm shift in the human gut microbiome study. Clin Microbiol Infect 2012; 18:1185-1193. PubMed

2. Rossello-Mora R. DNA-DNA Reassociation Methods Applied to Microbial Taxonomy and Their Critical Evaluation. In: Stackebrandt E (ed),
Naphtol-AS-BI phosphohydrolase activities are present. Oxidase, nitrate reduction, indole formation, urease, arginine dihydrolase, $\alpha$ - and $\beta$ glucosidase, 6-phospho- $\beta$-galactosidase, arginine arylamidase, proline arylamidase, phenylalanine arylamidase, leucine arylamidase, pyroglutamic acid arylamidase, tyrosine arylamidase, glycine arylamidase, histidine arylamidase, glutamyl glutamic acid arylamidase and serine arylamidase, mannose and raffinose fermentation activities are absent. Cells are susceptible to imipenem, ciprofloxacin, metronidazole, nitrofurantoin and rifampicin, but resistant to penicillin G, amoxicillin, amoxicillin-clavulanic acid, erythromycin, vancomycin, gentamicin, doxycycline, ceftriaxone and trimethoprim/sulfamethoxazole. The $\mathrm{G}+\mathrm{C}$ content of the genome is $58.6 \%$. The $16 \mathrm{~S}$ rRNA and genome sequences are deposited in Genbank under accession numbers JN837494 and CAHA00000000, respectively. The type strain ph8 $^{\mathrm{T}}(\mathrm{CSUR}=\mathrm{P} 186=$ DSM 25724) was isolated from the fecal flora of an obese patient in France.

work was funded by the Mediterranee-Infection foundation.

Molecular Identification, Systematics, and population Structure of Prokaryotes. Springer, Berlin, 2006, p. 23-50.

3. Kokcha S, Mishra AK, Lagier JC, Million M, Leroy Q, Raoult D, Fournier PE. Non contiguousfinished genome sequence and description of $\mathrm{Ba}-$ cillus timonensis sp. nov. Stand Genomic Sci 2012; 6:346-355. PubMed http://dx.doi.org/10.4056/sigs.2776064 
4. Lagier JC, El Karkouri K, Nguyen TT, Armougom F, Raoult D, Fournier PE. Non-contiguous finished genome sequence and description of Anaerococcus senegalensis sp. nov. Stand Genomic Sci 2012; 6:116-125. PubMed http://dx.doi.org/10.4056/sigs.2415480

5. Mishra AK, Lagier JC, Robert C, Raoult D, Fournier PE. Non-contiguous finished genome sequence and description of Clostridium senegalense sp. nov. Stand Genomic Sci 2012; 6:386-395. PubMed

6. Mishra AK, Gimenez G, Lagier JC, Robert C, Raoult D, Fournier PE. Non-contiguous finished genome sequence and description of Alistipes senegalensis sp. nov. Stand Genomic Sci 2012; 6:304-314. http://dx.doi.org/10.4056/sigs.2625821

7. Lagier JC, Armougom F, Mishra AK, Ngyuen TT, Raoult D, Fournier PE. Non-contiguous finished genome sequence and description of Alistipes timonensis sp. nov. Stand Genomic Sci 2012; 6:315-324. PubMed http://dx.doi.org/10.4056/sigs.2685917

8. Mishra AK, Lagier JC, Robert C, Raoult D, Fournier PE. Non-contiguous finished genome sequence and description of Peptoniphilus timonensis sp. nov. Stand Genomic Sci 2012; 7:111. http://dx.doi.org/10.4056/sigs.2956294

9. Mishra AK, Lagier JC, Rivet R, Raoult D, Fournier $P E$. Non-contiguous finished genome sequence and description of Paenibacillus senegalensis sp. nov. Stand Genomic Sci 2012; 7:70-81. http://dx.doi.org/10.4056/sigs.3054650

10. Lagier JC, Gimenez G, Robert C, Raoult D, Fournier PE. Non-contiguous finished genome sequence and description of Herbaspirillum massiliense sp. nov. Stand Genomic Sci 2012; 7:200-209. PubMed http://dx.doi.org/10.4056/sigs.3086474

11. Roux V, El Karkouri K, Lagier JC, Robert C, Raoult D. Non-contiguous finished genome sequence and description of Kurthia massiliensis sp. nov. Stand Genomic Sci 2012; 7:221-232. PubMed http://dx.doi.org/10.4056/sigs.3206554

12. Kokcha S, Ramasamy D, Lagier JC, Robert C, Raoult D, Fournier PE. Non-contiguous finished genome sequence and description of Brevibacterium senegalense sp. nov. Stand Genomic Sci 2012; 7:233-245. PubMed http://dx.doi.org/10.4056/sigs.3256677

13. Ramasamy D, Kokcha S, Lagier JC, N'Guyen TT, Raoult D, Fournier PE. Non-contiguous finished genome sequence and description of Aeromicrobium massilense sp. nov. Stand Genomic Sci 2012; 7:246-257. PubMed http://dx.doi.org/10.4056/sigs.3306717

14. Lagier JC, Ramasamy D, Rivet R, Raoult D, Fournier PE. Non-contiguous finished genome sequence and description of Cellulomonas massiliensis sp. nov. Stand Genomic Sci 2012; 7:258-270. PubMed http://dx.doi.org/10.4056/sigs.3316719

15. Rautio M, Eerola E, Vaisanen-Tunkelrott ML, Molitoris D, Lawson P, Collins MD, JousimiesSomer S. Reclassification of Bacteroides putredinis (Weinberg et al., 1937) in a new genus Alistipes gen. nov., as Alistipes putredinis comb. nov., and description of Alistipes finegoldii sp. nov., from human sources. Syst Appl Microbiol 2003; 26:182-188. PubMed http://dx.doi.org/10.1078/072320203322346029

16. Nagai F, Morotomi $M$, Watanabe $Y$, Sakon $H$, Tanaka R. Alistipes indinstinctus sp. nov. and Odoribacter laneus sp. nov., common members of the human intestinal microbiota isolated from faeces. Int J Syst Evol Microbiol 2010; 60:12961302. PubMed http://dx.doi.org/10.1099/ijs.0.014571-0

17. Song Y, Kononen E, Rautio M, Liu C, Bryk A, Eerola E, Finegold SM. Alistipes onderdonkii sp. nov. and Alistipes shahii sp. nov., of human origin. Int J Syst Evol Microbiol 2006; 56:19851990. PubMed http://dx.doi.org/10.1099/ijs.0.64318-0

18. Fenner L, Roux V, Ananian P, Raoult D. Alistipes finegoldii in blood cultures from colon cancer patients. Emerg Infect Dis 2007; 13:1260-1262. PubMed http://dx.doi.org/10.3201/eid1308.060662

19. Brook I. Clinical review: bacteremia caused by anaerobic bacteria in children. Crit Care 2002; 6:205-211. PubMed http://dx.doi.org/10.1186/cc1490

20. Rautio M, Saxen H, Siitonen A, Nikku R, Jousimies-Somer $\mathrm{H}$. Bacteriology of histopathologically defined appendicitis in children. Pediatr Infect Dis / 2000; 19:1078-1083. PubMed http://dx.doi.org/10.1097/00006454200011000-00010

21. Field D, Garrity G, Gray T, Morrison N, Selengut J, Sterk P, Tatusova T, Thomson N, Allen MJ, Angiuoli SV, et al. The minimum information about a genome sequence (MIGS) specification. 
Nat Biotechnol 2008; 26:541-547. PubMed

http://dx.doi.org/10.1038/nbt1360

22. Woese CR, Kandler O, Wheelis ML. Towards a natural system of organisms: proposal for the domains Archaea, Bacteria, and Eukarya. Proc Natl Acad Sci USA 1990; 87:4576-4579. PubMed http://dx.doi.org/10.1073/pnas.87.12.4576

23. Validation List No. 143. Int J Syst Evol Microbiol 2012; 62:1-4.

24. Krieg NR, Ludwig W, Euzéby J, Whitman WB. Phylum XIV. Bacteroidetes phyl. nov. In: Krieg NR, Staley JT, Brown DR, Hedlund BP, Paster BJ, Ward NL, Ludwig W, Whitman WB (eds), Bergey's Manual of Systematic Bacteriology, Second Edition, Volume 4, Springer, New York, 2011, p. 25.

25. Krieg NR. Class I. Bacteroidia class. nov. In: Krieg NR, Staley JT, Brown DR, Hedlund BP, Paster BJ, Ward NL, Ludwig W, Whitman WB (eds), Bergey's Manual of Systematic Bacteriology, Second Edition, Volume 4, Springer, New York, 2011, p. 25.

26. Krieg NR. Order I. Bacteroidales ord. nov. In: Krieg NR, Staley JT, Brown DR, Hedlund BP, Paster BJ, Ward NL, Ludwig W, Whitman WB (eds), Bergey's Manual of Systematic Bacteriology, Second Edition, Volume 4, Springer, New York, 2011, p. 25.

27. Krieg NR, Staley JT, Brown DR, Hedlund BP, Paster BJ, Ward NL, Ludwig W, Whitman WB. Family III. Rikenellaceae fam. nov. In: Krieg NR, Staley JT, Brown DR, Hedlund BP, Paster BJ, Ward NL, Ludwig W, Whitman WB (eds), Bergey's Manual of Systematic Bacteriology, Second Edition, Volume 4, Springer, New York, 2011, p. 54.

28. Validation List no. 94. Validation of publication of new names and new combinations previously effectively published outside the IJSEM. Int I Syst Evol Microbiol 2003; 53:1701-1702. PubMed http://dx.doi.org/10.1099/ijs.0.03001-0

29. Rautio M, Eerola E, Väisänen-Tunkelrott ML, Molitoris D, Lawson P, Collins MD, JousimiesSomer H. Reclassification of Bacteroides putredinis (Weinberg et al., 1937) in a new genus Alistipes gen. nov., as Alistipes putredinis comb. nov., and description of Alistipes finegoldii sp. nov., from human sources. Syst Appl Microbiol
2003; 26:182-188. PubMed

http://dx.doi.org/10.1078/072320203322346029

30. Ashburner M, Ball CA, Blake JA, Botstein D, Butler $\mathrm{H}$, Cherry JM, Davis AP, Dolinski K, Dwight SS, Eppig JT, et al. Gene ontology: tool for the unification of biology. The Gene Ontology Consortium. Nat Genet 2000; 25:25-29. PubMed http://dx.doi.org/10.1038/75556

31. List of Prokaryotic names with Standing in Nomenclature. http://www.bacterio.cict.fr

32. Stackebrandt E, Ebers J. Taxonomic parameters revisited: tarnished gold standards. Microbiol Today 2006; 33:152-155.

33. Seng P, Drancourt M, Gouriet F, La Scola B, Fournier PE, Rolain JM, Raoult D. Ongoing revolution in bacteriology: routine identification of bacteria by matrix-assisted laser desorption ionization time-of-flight mass spectrometry. Clin Infect Dis 2009; 49:543-551. PubMed http://dx.doi.org/10.1086/600885

34. Prodigal. http://prodigal.ornl.gov/

35. Lowe TM, Eddy SR. t-RNAscan-SE: a program for imroved detection of transfer RNA gene in genomic sequence. Nucleic Acids Res 1997; 25:955-964. PubMed

36. Lagesen K, Hallin P, Rodland EA, Staerfeldt HH, Rognes T, Ussery DW. RNAmmer: consistent and rapid annotation of ribosomal RNA genes. Nucleic Acids Res 2007; 35:3100-3108. PubMed http://dx.doi.org/10.1093/nar/gkm160

37. Bendtsen JD, Nielsen H, von Heijne G, Brunak S. Improved prediction of signal peptides: SignalP 3.0. J Mol Biol 2004; 340:783-795. PubMed http://dx.doi.org/10.1016/j.jmb.2004.05.028

38. Krogh A, Larsson B, von Heijne G, Sonnhammer EL. Predicting transmembrane protein topology with a hidden Markov model: application to complete genomes. J Mol Biol 2001; 305:567580. PubMed http://dx.doi.org/10.1006/jmbi.2000.4315

39. Lechner M, Findeib S, Steiner L, Marz M, Stadler PF, Prohaska SJ. Proteinortho: Detection of (Co)orthologs in large-scale analysis. BMC Bioinformatics 2011; 12:124. PubMed http://dx.doi.org/10.1186/1471-2105-12-124 